\title{
Separation of $\mathrm{Am}(\mathrm{III})$ from $\mathrm{Cm}(\mathrm{III})$ and Eu(III) by electro-spun polystyrene- immobilized CyMe4-BTPhen
}

Article

Accepted Version

Creative Commons: Attribution-Noncommercial-No Derivative Works 4.0

Afsar, A., Westwood, J., Distler, P., Harwood, L. M., Mohan, S., John, J. and Davis, F. J. (2018) Separation of Am(III) from $\mathrm{Cm}$ (III) and Eu(III) by electro-spun polystyrene- immobilized CyMe4-BTPhen. Tetrahedron, 74 (38). pp. 5258-5262. ISSN 0040-4020 doi: https://doi.org/10.1016/j.tet.2018.04.037 Available at https://centaur.reading.ac.uk/80776/

It is advisable to refer to the publisher's version if you intend to cite from the work. See Guidance on citing.

To link to this article DOI: http://dx.doi.org/10.1016/j.tet.2018.04.037

Publisher: Elsevier

All outputs in CentAUR are protected by Intellectual Property Rights law, including copyright law. Copyright and IPR is retained by the creators or other copyright holders. Terms and conditions for use of this material are defined in the End User Agreement.

www.reading.ac.uk/centaur 
Central Archive at the University of Reading

Reading's research outputs online 


\section{Graphical Abstract}

To create your abstract, type over the instructions in the template box below.

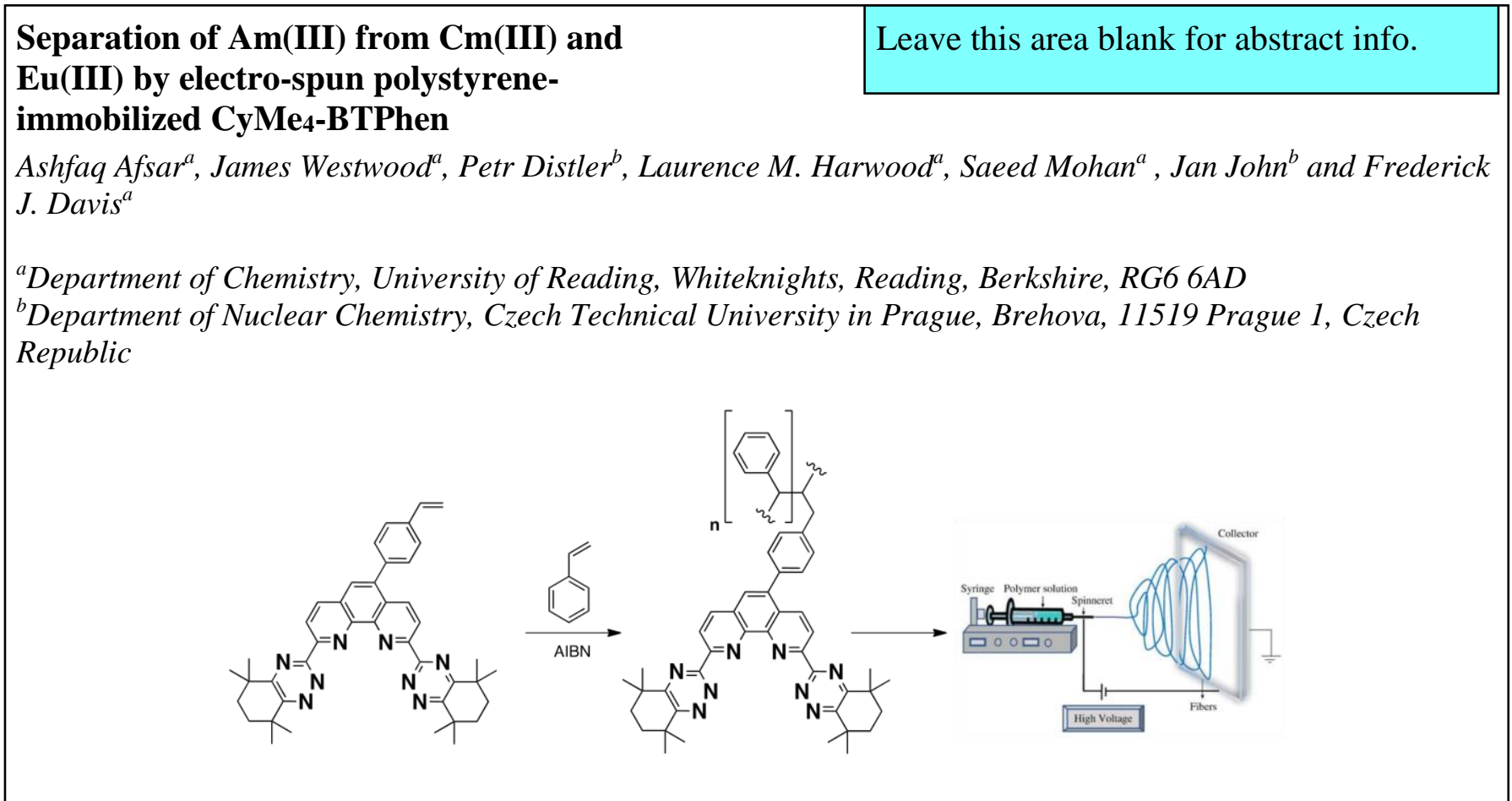

Fonts or abstract dimensions should not be changed or altered. 
Tetrahedron

journal homepage: www.elsevier.com

\title{
Separation of Am(III) from Cm(III) and Eu(III) by electro-spun polystyrene- immobilized $\mathrm{CyMe}_{4}-\mathrm{BTPhen}$
}

\author{
Ashfaq Afsar ${ }^{\mathrm{a}}$, James Westwood ${ }^{\mathrm{a}}$, Petr Distler ${ }^{\mathrm{b}}$, Laurence M. Harwood ${ }^{\mathrm{a}}$, Saeed \\ Mohan $^{\mathrm{a}}$, Jan John ${ }^{\mathrm{b}}$ and Frederick J. Davis ${ }^{\mathrm{a}}$
}

${ }^{a}$ Department of Chemistry, University of Reading, Whiteknights, Reading, Berkshire RG6 6AD, UK. E-mail: l.m.harwood@ reading.ac.uk

${ }^{b}$ Department of Nuclear Chemistry, Czech Technical University in Prague, Břehová 7, 11519 Prague 1, Czech Republic. E-mail: jan.john@fifi.cvut.cz.

\section{ARTICLE INFO}

\section{ABSTRACT}

\section{Article history:}

Received

Received in revised form

Accepted

Available online

\section{Keywords:}

Spent Nuclear Fuel

$\mathrm{CyMe}_{4}$-BTPhen

Americium

Europium

Curium
The synthesis of a novel 5-(4-vinylphenyl)-CyMe 4 -BTPhen actinide selective ligand using selenium free synthetic procedures is reported. For the first time, we report the electrospinning of this actinide selective ligand into a polystyrene fiber and investigate its selective removal of $\mathrm{Am}$ (III) from $\mathrm{Eu}(\mathrm{III})$ and $\mathrm{Am}$ (III) from $\mathrm{Cm}$ (III). The functionalized fibres demonstrated a separation factor of $\mathrm{SF}_{\mathrm{Am} / \mathrm{Eu}} \sim 57$ and a small, but significant separation of $\mathrm{SF}_{\mathrm{Am} / \mathrm{Cm}} \sim 2.9$ at $4 \mathrm{M}$ $\mathrm{HNO}_{3}$.

\section{Introduction}

The generation of used nuclear fuel (commonly known as "spent nuclear fuel", SNF) has contributed to the global accumulation of actinides, where the separation of these radiotoxic elements is strongly affected by the presence of other elements, including transition metals and lanthanides, which compete for the binding sites in the ligands used for their separation. ${ }^{1-3}$ After the removal of uranium (U) and plutonium $(\mathrm{Pu})$ from the SNF by the currently employed PUREX process, most of the radiotoxicity and heat-load of the fuel arises from the presence of the minor actinides (americium, curium and neptunium), even though they only account for a small proportion of the waste $(\sim 0.1 \%) .{ }^{4}$ Selective separation of the actinides $\mathrm{Am}$ (III) and $\mathrm{Cm}$ (III) from fission products and closely related lanthanides has been previously achieved using soft $N$ donor ligands such as (1), (2) and (3), which contain the 1,2,4triazine moiety. ${ }^{5,6}$

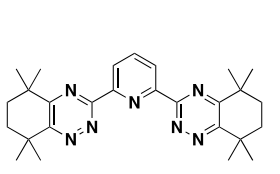

(1)

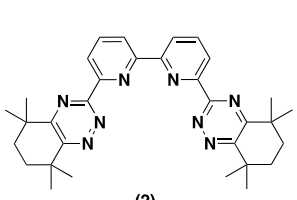

(2)

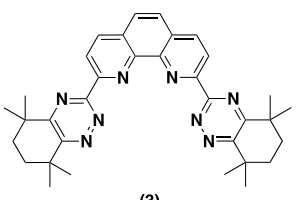

Fig 1. Structures of $\mathrm{CyMe}_{4}-\mathrm{BTP}(\mathbf{1}), \mathrm{CyMe}_{4}-\mathrm{BTBP}(\mathbf{2})$ and $\mathrm{CyMe}_{4^{-}}$ BTPhen (3).

2009 Elsevier Ltd. All rights reserved.

It is generally accepted that one of the contributors to this selectivity is due to the more radially expanded nature of the $5 f$ obitals of the actinides compared to the $4 f$-orbitals of the lanthanides. ${ }^{7,8}$ It is rationalized that this subtle difference means that soft $\mathrm{N}$-donor extractants have increased ligand-actinide bond covalency and hence selectivity over the lanthanides. More recently, substitution at different positions of the 1,10phenanthroline core in (3) has provided the ability to fine-tune the ligands electronically to be even more selective towards actinides over lanthanides. The ligand efficiency for the extraction of the actinides over lanthanides by some electronically modulated ligands has been studied and reported. ${ }^{9,10}$ Furthermore, Br-CyMe 4 -BTPhen (4) and 5-(4hydroxyphenyl)-CyMe 4 -BTPhen (5) (Fig. 2) have been shown to exhibit slight, but significant selectivity for Am(III) over Cm(III), elements that are adjacent to each other in the periodic table. ${ }^{11}$

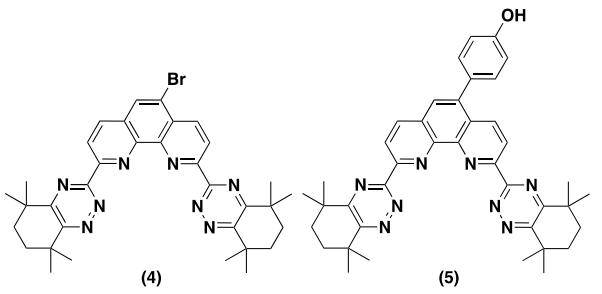

Fig. 2. Structures of Br-CyMe $e_{4}-\mathrm{BTPhen}$ (4) and 5-(4-hydroxyphenyl)$\mathrm{CyMe}_{4}-\mathrm{BTPhen}(\mathbf{5})$ 
The ligands shown in Fig. 2 provide a means of amplifying the very small differences in the covalent interactions of Am(III) and $\mathrm{Cm}$ (III) with the ligands by subtle electronic modulation with 5bromo- (4) and 5-(4-hydrxyphenyl)- (5) substitutents, revealing separation factors for $\mathrm{Am}(\mathrm{III})$ over $\mathrm{Cm}$ (III) $\left(\mathrm{SF}_{\mathrm{Am} / \mathrm{Cm}}\right)$ as high as 7.9,10

There are several partitioning processes that have been proposed and studied to separate Am(III) from Eu(III), but most of these processes focus entirely on solvent extraction processes which possess certain disadvantages, including the need for large volumes of organic solvents and degradation of the solvents over time, resulting in reduced performance and efficiency. Quite often these liquid-liquid extraction systems require the use of phase modifiers to optimize extraction and third phase formation is usually encountered. ${ }^{12}$ Extraction systems based on immobilized extractants would remove the need for an organic solvent. Synthesis of ligand (5) enabled immobilization of $\mathrm{CyMe}_{4}-\mathrm{BTPhen}$ ligands onto solid supports, notably magnetic nano-particles (MNPs) and macroscopic silica gel, where their ability to separate $\mathrm{Am}$ (III) from $\mathrm{Eu}(\mathrm{III})$ has been previously demonstrated. ${ }^{13,14}$ Related ligands have also been functionalized by cross-linking into PVB (polyvinyl benzyl) polymers and their Am(III) extraction ability investigated by use of an ion-exchange resin. ${ }^{15}$ The ability of these solid supports to be implemented in the extraction of $\mathrm{Am}$ (III) from $\mathrm{Eu}$ (III) in solutions of up to $4 \mathrm{M}$ $\mathrm{HNO}_{3}$ has opened up an area of research geared towards functionalizing solid materials for selective actinide separation. Moving towards solid supported processes, and in particular using column separation techniques, will ultimately help reduce the solvent waste generated by continuous solvent extraction processes.

In this work, we outline the synthesis of novel 5-(4vinylphenyl)-CyMe ${ }_{4}$-BTPhen (6) using a selenium-free synthetic protocol and report the ability of this ligand to separate Am(III) from $\mathrm{Eu}(\mathrm{III})$ and $\mathrm{Am}(\mathrm{III})$ from $\mathrm{Cm}(\mathrm{III})$ when electro-spun into fibres of polystyrene (8) (Scheme 1).

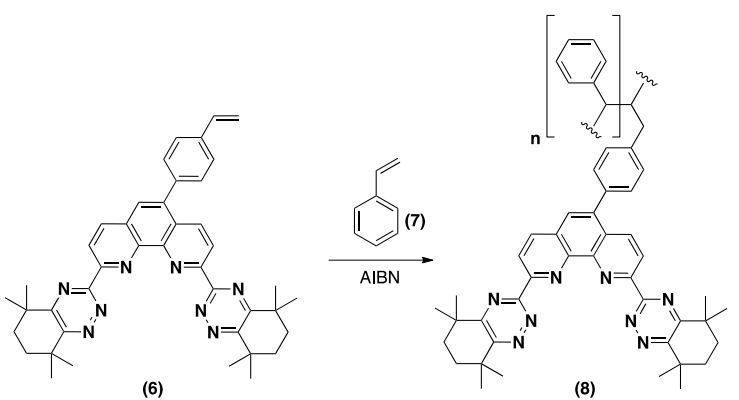

Scheme 1. Synthesis of Polystyrene immobilized $\mathrm{CyMe}_{4}-\mathrm{BTPhen}(\mathbf{8})$

\section{Results and Discussion}

\subsection{Synthesis of 5-(4-vinylphenyl)-CyMe ${ }_{4}-B T P h e n(6)$}

Until recently, the synthesis of the core $\mathrm{CyMe}_{4}-\mathrm{BTPhen}(\mathbf{3})$ unit required the use of stoichiometric amounts of toxic selenium dioxide to generate the phenanthroline bis-aldehyde, required for the one-pot conversion to the phenanthroline bis-nitrile, where nitrile functional groups are key precursors to produce many heterocyclic cores. ${ }^{16}$ Edwards et al. demonstrated that the benzylic oxidation could be achieved by per-chlorination of the methyl groups in 2,9-dimethyl-1,10-phenanthroline and subsequent hydrolysis/methylation to give a bis-ester. ${ }^{10,17}$ Conversion to a bis-amide and dehydration afforded the bisnitrile compound required to develop BTPhen (3) related ligands. ${ }^{14}$ In an alternative approach, the installation of nitrile groups into 1,10-phenanthroline derivatives has been achieved using photochemical reactions, where $\mathrm{C}-\mathrm{H}$ functionalization of substituted phenanthroline units using a transient $\alpha$-amido radical afforded phenanthroline bis-amides, which were then dehydrated to the corresponding bis-nitriles by in situ preparation of Vilsmeier-Haack reagent. ${ }^{18}$ Following these developments in the synthesis of BTPhen ligands, Br-CyMe 4 -BTPhen (4) was synthesized using the improved synthetic protocol (Scheme 2). ${ }^{10,14}$ Suzuki-Miyaura cross coupling with 4-vinylphenyl boronic acid afforded the novel 5-(4-vinylphenyl)-CyMe $4_{4}^{-}$ BTPhen $(\mathbf{6})$ required for bulk polymerization with styrene.

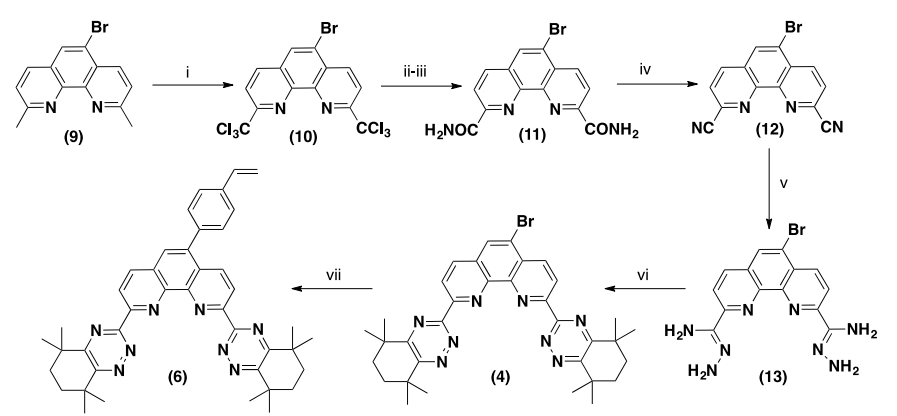

Scheme 2. Synthesis of 5-(4-vinylphenyl)-CyMe ${ }_{4}-\mathrm{BTPhen}$ (6): i) NCS, $m$-CPBA, $\mathrm{CHCl}_{3}, 90 \%$; ii) $\mathrm{H}_{2} \mathrm{SO}_{4}$ then $\mathrm{MeOH}, 70 \%$; iii) $\mathrm{NH}_{4} \mathrm{Cl}, \mathrm{NH}_{4} \mathrm{OH}$, $89 \%$; iv) $\mathrm{POCl}_{3}, 90 \%$; v) $\mathrm{N}_{2} \mathrm{H}_{4} \cdot \mathrm{H}_{2} \mathrm{O}$ (64\%), DMSO, 60\%; vi) $3,3,6,6-$ tetramethylcyclohexan-1,2-dione, THF, $\mathrm{Et}_{3} \mathrm{~N}, 55 \%$; vii) 4-vinylboronic acid, $\mathrm{Pd}\left(\mathrm{PPh}_{3}\right)_{4}, \mathrm{~K}_{2} \mathrm{CO}_{3}$, PhMe:EtOH: $\mathrm{H}_{2} \mathrm{O}, 50 \%$;

Polystyrene units can be polymerized in bulk at temperatures of $>100{ }^{\circ} \mathrm{C}$ without the need for the addition of an initiator, where control of the polymers molecular weight is lost. More controlled polymerization can take occur at lower temperatures (ca. $55-60{ }^{\circ} \mathrm{C}$ ), with the addition of initiators, typically benzoyl peroxide or AIBN (azo-bis-isobutyronitrile). ${ }^{19}$ 5-(4Vinylphenyl)-CyMe $\mathrm{M}_{4}-\mathrm{BTPhen}$ (6) was subsequently copolymerized with styrene using using AIBN as the initiator (Scheme 1). Electrospinning the 5-(4-vinylphenyl)-CyMe $4^{-}$ BTPhen-styrene co-polymer $(\mathbf{8})$ produced fine yellowish fibres, resembling cotton-wool.

\subsection{Characterization of Electro-spun Fibers}

The polystyrene-immobilized $\mathrm{CyMe}_{4}$-BTPhen fibres (8) were characterized to assess the immobilization of the ligand and to investigate structural features using Fourier transform infrared spectroscopy (FT-IR), elemental analysis (ESI) and scanning electron microscopy (SEM) (Fig. 3).

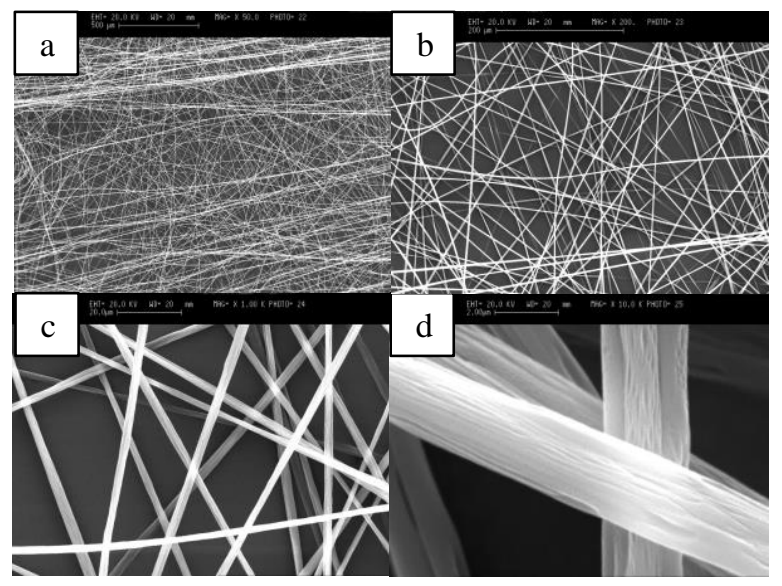

Fig 3. SEM images of polystyrene-immobilized $\mathrm{CyMe}_{4}$-BTPhen fibres (8). Horizontal axis: a) $500 \mu \mathrm{m}$ b) $200 \mu \mathrm{m}$ c) $20 \mu \mathrm{m} \mathrm{d)} 2.0 \mu \mathrm{m}$ 
The SEM images at different magnifications clearly show the regularity in diameter and high surface area of these fine fibres and elemental analysis reveals the incorporation of nitrogen into the co-polymer (ESI). The FT-IR spectrum of the electro-spun polystyrene-immobilized $\mathrm{CyMe}_{4}-\mathrm{BTPhen}$ fibres (8) shows overlapping bands due to aromatic $\mathrm{C}-\mathrm{C}$ stretching of the styrene residues, and additional aromatic vibrations for the ligand (ESI). The GPC (gel permeation chromatography) eluogram of electrospun polystyrene immobilized $\mathrm{CyMe}_{4}-\mathrm{BTPhen}$ fibers (8) is shown below in Fig. 4. The overall distribution values revealed for $\mathrm{M}_{\mathrm{n}}$ were 36.10 and $7.0 \mathrm{~kg} \mathrm{~mol}^{-1}$ respectively with dispersion values $(\bigoplus)$ of 1.95 and 2.00 respectively.

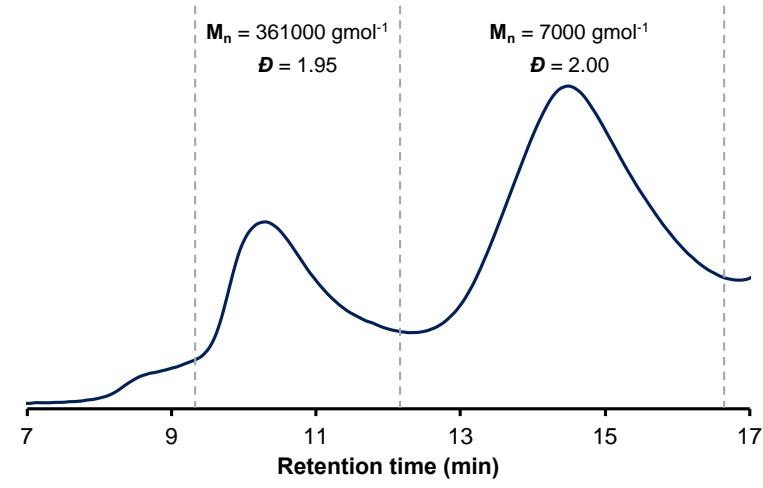

Fig. 4. GPC eluogram of polystyrene-immobilized $\mathrm{CyMe}_{4}-\mathrm{BTPhen}$ fibres (8)

\subsection{Extraction Data}

The ability for polystyrene immobilized $\mathrm{CyMe}_{4}-\mathrm{BTPhen}(\mathbf{8})$ to extract $\mathrm{Am}$ (III) from $\mathrm{Eu}(\mathrm{III})$ and $\mathrm{Am}(\mathrm{III})$ from $\mathrm{Cm}$ (III) across a range of $\mathrm{HNO}_{3}$ concentration was investigated at the Czech Technical University in Prague. The extraction results for $\mathrm{Am}(\mathrm{III}) / \mathrm{Eu}(\mathrm{III})$ by $(\mathbf{8})$ showed good distribution ratios for both $\operatorname{Am}(\mathrm{III})\left(D_{\mathrm{wAm}}=490 \pm 24\right)$ and $\mathrm{Eu}(\mathrm{III})\left(D_{\mathrm{wEu}}=66 \pm 1\right)$ at 0.001 $\mathrm{M} \mathrm{HNO}_{3}$ with a separation factor of $\mathrm{SF}_{\mathrm{Am} / \mathrm{Eu}}=7.40 \pm 0.24$ (Table 2). However, these values are much lower than those obtained for the same $\mathrm{CyMe}_{4}-\mathrm{BTPhen}$ unit covalently bound to $\mathrm{SiO}_{2}$-coated $\operatorname{MNPs}\left(D_{\mathrm{Am}}=1168.8 \pm 79.1\right.$ and $\left.D_{\mathrm{Eu}}=701.4 \pm 32.4\right) .{ }^{20}$ Increasing the $\mathrm{HNO}_{3}$ concentration led to an increase in Am(III) extraction $\left(D_{\mathrm{wAm}}=781 \pm 46\right)$, and a decrease in $\mathrm{Eu}(\mathrm{III})$ extraction $\left(D_{\mathrm{wEu}}=20 \pm 1\right)$ giving a separation factor of $\mathrm{SF}_{\mathrm{Am} / \mathrm{Eu}}=39.1 \pm 1.5$ at $0.1 \mathrm{M} \mathrm{HNO}$. A decrease in both $\mathrm{Am}$ (III) and $\mathrm{Eu}(\mathrm{III})$ extraction was observed for (8) upon increasing $\mathrm{HNO}_{3}$ concentration to both $1 \mathrm{M}$ and $4 \mathrm{M}$ (Fig. 5). $D_{\mathrm{wAm}}$ remained much greater than $D_{\mathrm{wEu}}$ in both cases and at $4 \mathrm{M} \mathrm{HNO}_{3}$ the extraction of $\mathrm{Eu}(\mathrm{III})$ dropped to $D_{\mathrm{wEu}} \sim 3.3 \pm 0.4$ giving a separation factor $\mathrm{SF}_{\mathrm{Am} / \mathrm{Eu}} \sim 5$ 57. Althrough these results follow the same trend exhibited by $\mathrm{CyMe}_{4}$-BTPhen ligands when immobilized onto other solid supported materials they are significantly lower than the results obtained for our previously studied model of $\mathrm{CyMe}_{4^{-}}$ BTPhen $\mathrm{SiO}_{2}$-coated MNPs at $4 \mathrm{M} \mathrm{HNO}_{3}$ where a $\mathrm{SF}_{\mathrm{Am} / \mathrm{Eu}} \approx 1700$ \pm 300 was obtained. ${ }^{20}$ This may be due to the hydrophobic nature of the fibres.

\begin{tabular}{|c|c|c|c|c|c|c|c|c|c|}
\hline $\mathbf{c}\left(\mathbf{H N O}_{3}\right)$ & \multicolumn{3}{|c|}{$\mathbf{D}_{\mathbf{w}}(\mathbf{A m})$} & \multicolumn{3}{c|}{$\mathbf{D}_{\mathbf{w}}(\mathbf{E u})$} & \multicolumn{3}{c|}{ SF(Am/Eu) } \\
\hline $\mathbf{0 . 0 0 1}$ & 490 & $+/-$ & 24 & 66 & $+/-$ & 1 & 7.40 & $+/-$ & 0.24 \\
\hline $\mathbf{0 . 1}$ & 781 & $+/-$ & 46 & 20 & $+/-$ & 1 & 39.1 & $+/-$ & 1.5 \\
\hline $\mathbf{1}$ & 387 & $+/-$ & 17 & 7.7 & $+/-$ & 0.2 & 50 & $+/-$ & 2 \\
\hline $\mathbf{4}$ & 188 & $+/-$ & 7 & 3.3 & $+/-$ & 0.4 & 57.1 & $+/-$ & 4.1 \\
\hline
\end{tabular}

Table 1. Extraction of $\mathrm{Am}(\mathrm{III})$ and $\mathrm{Eu}(\mathrm{III})$ by $(\mathbf{8})$ as a function of nitric acid concentration

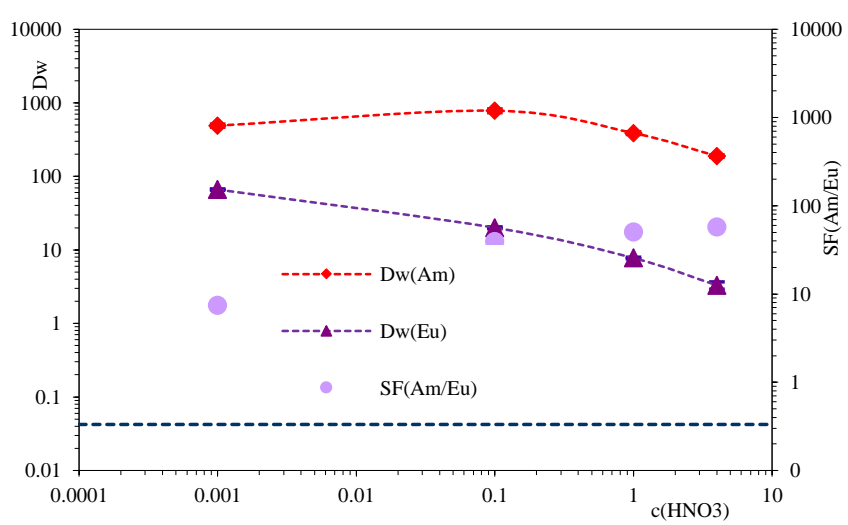

Fig. 5. Extraction of $\mathrm{Am}(\mathrm{IIII})$ and $\mathrm{Eu}(\mathrm{III})$ by $(\mathbf{8})$ as a function of nitric acid concentration

The results for $\mathrm{Am}(\mathrm{III}) / \mathrm{Cm}(\mathrm{III})$ selective extraction by $(\mathbf{8})$ are shown in Table 2 and Fig. 6. At low nitric acid concentration $(0.001 \mathrm{M})$ there is a very little selectivity between $\mathrm{Am}(\mathrm{III})$ and $\mathrm{Cm}(\mathrm{III})\left(\mathrm{SF}_{\mathrm{Am} / \mathrm{Cm}} \sim 1.1\right)$. An increase in extraction for both $\mathrm{Am}(\mathrm{III})$ and $\mathrm{Cm}$ (III) is observed upon increasing the concentration of $\mathrm{HNO}_{3}$ to $0.1 \mathrm{M}$ and at $1 \mathrm{M} \mathrm{HNO}_{3}$, there is a more significant extraction of $\mathrm{Am}(\mathrm{III})$ over $\mathrm{Cm}$ (III) giving a separation factor of $\mathrm{SF}_{\mathrm{Am} / \mathrm{Cm}} \sim 1.7$. Finally, at $4 \mathrm{M} \mathrm{HNO}_{3}$, conditions akin to those found in reprocessing of spent nuclear fuel, a separation factor $\mathrm{SF}_{\mathrm{Am} / \mathrm{Cm}} \sim 2.9$ is observed.

\begin{tabular}{|c|c|c|c|c|c|c|c|c|c|}
\hline $\mathbf{c}\left(\mathbf{H N O}_{3}\right)$ & \multicolumn{3}{|c|}{$\mathbf{D}_{\mathbf{w}}(\mathbf{A m}) *$} & \multicolumn{3}{c|}{$\mathbf{D}_{\mathbf{w}}(\mathbf{C m})$} & \multicolumn{3}{c|}{$\mathbf{S F}(\mathbf{A m} / \mathbf{C m})$} \\
\hline $\mathbf{0 . 0 0 1}$ & 371 & $+/-$ & 43 & 343 & $+/-$ & 27 & 1.1 & $+/-$ & 0.2 \\
\hline $\mathbf{0 . 1}$ & 543 & $+/-$ & 68 & 441 & $+/-$ & 39 & 1.2 & $+/-$ & 0.2 \\
\hline $\mathbf{1}$ & 350 & $+/-$ & 39 & 204 & $+/-$ & 12 & 1.7 & $+/-$ & 0.2 \\
\hline $\mathbf{4}$ & 151 & $+/-$ & 14 & 53 & $+/-$ & 3 & 2.9 & $+/-$ & 0.6 \\
\hline
\end{tabular}

Table 2. Extraction of Am(III) and Cm(III) by (8) as a function of nitric acid concentration (*values are from alpha measurement)

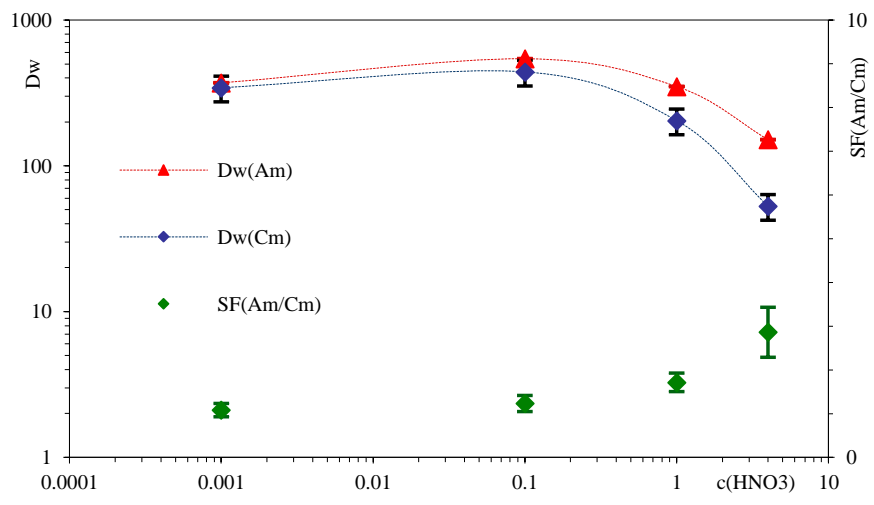

Fig. 6. Extraction of $\mathrm{Am}(\mathrm{III})$ and $\mathrm{Cm}(\mathrm{III})$ by $(\mathbf{8})$ as a function of nitric acid concentration

\section{Conclusions}

We have reported the synthesis of electro-spun polystyreneimmobilized $\mathrm{CyMe}_{4}$-BTPhen fibres that will selectively extract $\mathrm{Am}$ (III) from $\mathrm{Eu}$ (III) at $4 \mathrm{M} \mathrm{HNO}_{3}\left(\mathrm{SF}_{\mathrm{Am} / \mathrm{Eu}}>57\right)$. The fibres also exhibit exhibit a small but significant selectivity for Am(III) over its actinide neighbour $\mathrm{Cm}(\mathrm{III})$, with a of $\mathrm{SF}_{\mathrm{Am} / \mathrm{Cm}} \sim 3$. The $\mathrm{Am} / \mathrm{Cm}$ results are similar to separation factors achieved with other solid supported ligands.

The synthesis of novel 5-(4-vinylphenyl)-CyMe 4 -BTPhen was achieved by adapting the recently reported selenium-free 
synthetic approach towards the core BTPhen structure. Installation of the 5-(4-vinylphenyl) group enabled efficient copolymerization with styrene. Although the separation factor of this electro-spun polymer is lower than other previously reported solid supported ligands (e.g. MNPs and $\mathrm{SiO}_{2}$ ), this could be attributed to the hydrophobicity of the fibres.

\section{Experimental}

\subsection{Extraction Studies}

The aqueous solutions for the solvent extraction experiments were prepared by spiking nitric acid solutions $(0.001-4 \mathrm{M})$ with stock solutions of ${ }^{241} \mathrm{Am},{ }^{152} \mathrm{Eu}$ and ${ }^{244} \mathrm{Cm}$ and then adding 1.000 $\mu \mathrm{L}$ of spiked aqueous solution to $19.8 \mathrm{mg}$ of BTPhen-polystyrene (8) (V/m ratio: $\left.30.3 \mathrm{~mL} \mathrm{~g}^{-1}\right)$. The mixture was sonicated for 10 min and shaken (Heidolph Reax) at $1800 \mathrm{rpm}$ for $90 \mathrm{~min}$. After centrifuging for $2 \mathrm{~min}$, aliquots of the aqueous solutions (supernatant) were separated and taken for measurements.

Quantitative measurements of the distribution weight ratios, $D_{w}$, were calculated (Equation 1), where $A_{o}$ is the activity of the uncontacted aqueous phase, $A_{s}$ is the activity of the aqueous phase after contact, $w$ is the weight of (8) and $v$ is the volume in contact with the sample. ${ }^{21}$ These values represent the ratio between the radioactivity ( $\alpha$ - and $\gamma$ - emissions) of each isotope in the standard solution and the supernatant. The separation factor is $\mathrm{SF}_{\mathrm{Am} / \mathrm{Eu}}=D_{\mathrm{Am}} / D_{\mathrm{Eu}}$ or $\mathrm{SF}_{\mathrm{Am} / \mathrm{Cm}}=D_{\mathrm{Am}} / D_{\mathrm{Cm}}$. Extractions were studied at nitric acid concentrations of $0.001 \mathrm{M}, 0.1 \mathrm{M}, 1 \mathrm{M}$ and $4 \mathrm{M}$.

$$
D_{w}=\frac{\left(A_{o}-A_{S}\right)}{A_{s}} \times \frac{v}{w} \quad(\text { Equation } 1)
$$

\subsection{General Procedures}

All reagents were purchased from Alfar, Fisher or SigmaAldrich. All chemicals were of analytical grade and used as received without further purification unless otherwise stated. NMR spectra were recorded using either a Bruker AMX400 or an Avance DFX400 instrument. Deuterated chloroform $\left(\mathrm{CDCl}_{3}\right)$ and Deuterated DMSO (dimethyl sulfoxide- $\mathrm{d}_{6}$ ) were used as solvents. Chemical shifts ( $\delta$ values) are reported in parts per million (ppm) with the abbreviations s, d, t, q, qn, sx, dd, ddd and br denoting singlet, doublet, triplet, quartet, quintet, sextet, double doublet, double double doublet and broad respectively. Coupling constants $(J)$ are quoted in Hertz. IR spectra were recorded on a Perkin Elmer RX1 FT-IR instrument. All the melting points were determined on a Gallenkamp melting point apparatus. Mass spectra were recorded under conditions of electrospray ionization (ESI). The ions observed were quasimolecular ions $[\mathrm{MH}]^{+}$.The instrument used was an Xcalibur Tune 2.1 (SP1).

\subsection{Synthesis of 5-(4-vinylphenyl)-CyMe ${ }_{4}-B T P h e n(6)^{22}$}

A suspension of Br-CyMe ${ }_{4}$-BTPhen (4) (1.00 g, $\left.1.60 \mathrm{mmol}\right)$, tetrakis(triphenylphosphine)palladium(0) $(74 \mathrm{mg}, 0.05 \mathrm{mmol}$, $0.03 \mathrm{eq})$, 4-vinylphenylboronic acid $(0.28 \mathrm{~g}, 1.90 \mathrm{mmol}, 1.2 \mathrm{eq})$ and potassium carbonate $(0.66 \mathrm{~g}, 4.8 \mathrm{mmol}, 3 \mathrm{eq})$ in toluene (200 $\mathrm{mL})$, EtOH $(40 \mathrm{~mL})$ and $\mathrm{H}_{2} \mathrm{O}(40 \mathrm{~mL})$ was heated to reflux for $48 \mathrm{hr}$. The solution was then cooled to room temperature, diluted with water $(250 \mathrm{~mL})$ and extracted with $\mathrm{CHCl}_{3}(3 \times 100 \mathrm{~mL})$. The organic extracts were collected and dried over $\mathrm{MgSO}_{4}$ and concentrated in vacuo. The solid residue was triturated with $\mathrm{Et}_{2} \mathrm{O}$ $(100 \mathrm{~mL})$ and filtered to give the title compound $(\mathbf{6})$ as a yellow solid $(0.55 \mathrm{~g}, 50 \%)$. M.p: decomposed at $280{ }^{\circ} \mathrm{C} .{ }^{1} \mathrm{H}$ NMR $(400$ $\mathrm{MHz}, \mathrm{CDCl} 3) \delta 8.88(\mathrm{~d}, \mathrm{~J}=8.3 \mathrm{~Hz}, 1 \mathrm{H}), 8.79(\mathrm{~d}, \mathrm{~J}=8.7 \mathrm{~Hz}$, $1 \mathrm{H}), 8.51(\mathrm{~d}, \mathrm{~J}=8.6 \mathrm{~Hz}, 1 \mathrm{H}), 8.46(\mathrm{~d}, \mathrm{~J}=8.5 \mathrm{~Hz}, 1 \mathrm{H}), 7.88(\mathrm{~s}$, $1 \mathrm{H}), 7.63(\mathrm{~d}, \mathrm{~J}=8.2 \mathrm{~Hz}, 2 \mathrm{H}), 7.57(\mathrm{~d}, \mathrm{~J}=8.2 \mathrm{~Hz}, 2 \mathrm{H}), 6.86(\mathrm{dd}, \mathrm{J}$
$=17.6,10.9 \mathrm{~Hz}, 1 \mathrm{H}), 5.90(\mathrm{~d}, \mathrm{~J}=17.6 \mathrm{~Hz}, 1 \mathrm{H}), 5.38(\mathrm{~d}, \mathrm{~J}=11.2$ $\mathrm{Hz}, 1 \mathrm{H}), 1.91(\mathrm{~s}, 8 \mathrm{H}), 1.58(\mathrm{~s}, 12 \mathrm{H}), 1.54(\mathrm{~s}, 12 \mathrm{H}) ;{ }^{13} \mathrm{C} \mathrm{NMR}$ (101 MHz, CDCl3) $\delta 164.99,163.12,161.56,153.94,146.79$, 146.04, 139.57, 138.09, 137.61, 137.19, 136.26, 135.78, 130.21, $129.50,129.0,127.32,126.56,123.73,123.16,114.83,77.36$, 77.04, 76.72, 37.54, 36.62, 33.76, 29.86, 29.37; MASS SPECTRUM/ ? INFRA RED

\subsection{Synthesis of polystyrene-immobilized CyMe ${ }_{4}$-BTPhen ( 8 )}

Styrene 7 (4.0 g, $38 \mathrm{mmol})$ and AIBN (0.05 g, $0.3 \mathrm{mmol})$ were added to a polymerization tube followed by degassed $\mathrm{MeOH}$ $(100 \mathrm{~mL})$. 6 (0.2 g, $0.3 \mathrm{mmol})$ was added and the tube was submerged in a water bath and heated to $55{ }^{\circ} \mathrm{C}$ for $18 \mathrm{hr}$. The tube was cooled and the polymer formed was dissolved in DCM $(50 \mathrm{~mL})$ and then slowly added to cold $\mathrm{MeOH}(100 \mathrm{~mL})$. The solid polymer that precipitated was then collected by filtration and dried in a vacuum oven at $40{ }^{\circ} \mathrm{C}$ to give the title compound as a yellow solid $(2.5 \mathrm{~g})$.

\subsection{Electro-spinning of 8 into fibers}

Electrospinning was performed using a Glassman's high voltage power supply capable of delivering $0-30 \mathrm{kV}$ with respect to ground. Solutions of $\mathbf{8}(1 \mathrm{~g}$ in $3 \mathrm{~mL}$ THF) were loaded into a $5 \mathrm{~mL}$ disposable plastic syringe fitted with a 21 gauge needle $(0.514 \mathrm{~mm}$ nominal internal diameter) of length $40 \mathrm{~mm}$ to which the high voltage supply was attached. The solution flow rate was controlled by a Razel scientific syringe pump with flow rate set at approximately $2 \mathrm{~mL} \mathrm{hr}^{-1}$. The distance between the flat aluminium collection plate and needle tip was $15 \mathrm{~cm}$ and the applied voltage of $15 \mathrm{kV}$ was used for electrospinning. The room temperature at the time of spinning was $\sim 21^{\circ} \mathrm{C}$ and the relative humidity was $47 \%$.

\subsection{GPC Analysis}

Gel permeation chromatography (GPC) was conducted using an Agilent Technologies 1260 Infinity system and the data were processed using Agilent GPC/SEC software, with polystyrene being used as the calibrant. Samples for GPC analysis were dissolved in analytical grade THF $\left(2 \mathrm{mg} \mathrm{mL}^{-1}\right)$ with butylated hydroxytoluene (BHT) stabilizer, and run using the same solvent as the mobile phase; eluting through two Agilent PLgel $5 \mu \mathrm{m}$ MIXED-D $300 \times 7.5 \mathrm{~mm}$ columns in series.

\section{Acknowledgments}

Use of the Chemical Analysis Facility (CAF) and the Electron Microscopy Laboratory (EMLab) at the University of Reading is gratefully acknowledged. We thank Mr Tahkur Singh Babra for running GPC analysis on the fibres.

\section{References and notes}

1 P. J. Panak and A. Geist, Chem. Rev., 2013, 113, 1199-1236.

2 K. L. Nash, J. C. Braley, C. Wai and B. Mincher, Nucl. Energy Environ., 2010, 1046, 19-38.

3 K. . Nash and M. Nilsson, Reprocessing and Recycling of Spent Nuclear Fuel, Elsevier, 2015.

4 F. W. Lewis, L. M. Harwood, M. J. Hudson, M. G. B. Drew, J. F. Desreux, G. Vidick, N. Bouslimani, G. Modolo, A. Wilden, M. Sypula, T. H. Vu and J. P. Simonin, J. Am. Chem. Soc., 2011, 133, 13093-13102.

5 H. H. Dam, D. N. Reinhoudt and W. Verboom, Chem. Soc. Rev., 2007, 36, 367-377.

6 A. Leoncini, J. Huskens and W. Verboom, Chem. Soc. Rev., 2017, 46, 7229-7273.

I. Kirker and N. Kaltsoyannis, Dalt. Trans., 2011, 40, 124-131.

N. Kaltsoyannis, Inorg. Chem., 2013, 52, 3407-3413.

A. Afsar, D. M. Laventine, L. M. Harwood, M. J. Hudson and A. 
Geist, Chem. Commun., 2013, 49, 8534-6.

A. C. Edwards, C. Wagner, A. Geist, N. A. Burton, C. A. Sharrad, R. W. Adams, R. G. Pritchard, P. J. Panak, R. C. Whitehead and L. M. Harwood, Dalt. Trans., 2016, 45, 18102-18112.

A. Afsar, L. M. Harwood, M. J. Hudson, J. Westwood and A. Geist, Chem. Commun., 2015, 51, 5860-5863.

N. J. Williams, J. Dehaudt, V. S. Bryantsev, H. Luo, C. W. Abney and S. Dai, Chem. Commun., 2017, 53, 2744-2747.

A. Afsar, P. Distler, L. M. Harwood, J. John and J. Westwood, Chem. Commun., 2017, 53, 4010-4013.

14 A. Afsar, J. Cowell, P. Distler, L. Harwood, J. John and J. Westwood, Synlett, 2017, 28, 2795-2799.

15 M. A. Higginson, O. J. Marsden, P. Thompson, F. R. Livens and S. L. Heath, React. Funct. Polym., 2015, 91-92, 93-99.

$151-158$.
17

18

19
A. M. S. Garas and R. S. Vagg, J. Heterocycl. Chem., 2000, 37,

A. F. Larsen and T. Ulven, Org. Lett, 2011, 13, 3546-3548.

A. C. Edwards, A. Geist, U. Müllich, C. A. Sharrad, R. G.

Pritchard, R. C. Whitehead and L. M. Harwood, Chem. Commun., 2017, 53, 8160-8163.

F. J. Davis, Polymer Chemistry : a Practical Approach, Oxford University Press, 2004

A. Afsar, L. M. Harwood, M. J. Hudson, P. Distler and J. John, Chem. Commun., 2014, 50, 15082-15085.

K. N. Tevepaugh, J. Coonce, S. Tai, L. H. Delmau, J. D. Carrick and D. D. Ensor, J. Radioanal. Nucl. Chem., 2017, 314, 371-376. H. Li, T. L. Tam, Y. M. Lam, S. G. Mhaisalkar and A. C. Grimsdale, Org. Lett., 2011, 13, 46-49. 